\title{
HARTMANN, Peter-Claus, Kurmainz, das Reichserzkanzleramt und das Reich am Ende des Mittelalters und im 16. und 17. Jahrhundert
}

Pierre Monnet

\section{(2) OpenEdition}

Édition électronique

URL : http://journals.openedition.org/ifha/1360

DOI : 10.4000/ifha. 1360

ISSN : 2198-8943

Éditeur

IFRA - Institut franco-allemand (sciences historiques et sociales)

Référence électronique

Pierre Monnet, " HARTMANN, Peter-Claus, Kurmainz, das Reichserzkanzleramt und das Reich am Ende des Mittelalters und im 16. und 17. Jahrhundert », Revue de I'IFHA [En ligne], Date de recension, mis en ligne le 01 janvier 1999, consulté le 22 septembre 2020. URL : http://journals.openedition.org/ifha/ 1360 ; DOI : https://doi.org/10.4000/ifha.1360

Ce document a été généré automatiquement le 22 septembre 2020.

(C)IFHA 


\title{
HARTMANN, Peter-Claus, Kurmainz, das Reichserzkanzleramt und das Reich am Ende des Mittelalters und im 16. und 17. Jahrhundert
}

\author{
Pierre Monnet
}

Ces deux recueils contiennent les actes de rencontres consacrées à l'étude du pouvoir, des fonctions et du rôle religieux et culturel de l'archevêque de Mayence, primat de Germanie, premier électeur du roi des Romains, archichancelier de l'Empire pour le royaume de Germanie, chef de la chancellerie royale et président de la diète d'Empire, que les théoriciens des institutions de l'Empire ont longtemps qualifié de »second personnage de l'État après l'empereur«. L'électeur ecclésiastique mayençais ne fut pas en effet un prince d'Empire comme les autres et l'évolution de ses différentes titulatures a bien reflété la patiente construction d'un ensemble devenu cohérent de responsabilités (Ernst SCHUBERT). Mais, ainsi que l'a montré en particulier la première rencontre, tous les attributs à l'instant énumérés ne lui furent pas toujours accordés sans discussion (Peter Claus HARTMANN). L'archevêque de Mayence dut ainsi marquer et défendre son territoire: par les tombeaux (Verena KESSEL, politique sépulcrale poursuivie aux XVe et XVe ss. comme le montre la contribution de Nicole BEYER dans le second volume); par la prise en compte de l'héritage de Boniface pour asseoir sa primatie (Georg MAY); par la mise en œuvre d'un pouvoir politique propre et réformé afin de conserver la chancellerie de la Chambre impériale de justice créée en 1495 (Bernhard DIESTELKAMP), la direction de la désignation électorale du roi-empereur (Susanne SCHLÖSSER) et les présidence et préséance au sein de la Diète d'Empire, du Reichstag (Ka rl HÄRTER). Après cet examen approfondi des fonctions de l'archevêqueélecteur-archicancelier, et de leur consolidation par les différents princes mayençais, le second volume s'est intéressé de plus près à la pratique politique et institutionnelle de ces pouvoirs et privilèges dont la réunion sur une seule tête n'allait pas sans contradictions. Ainsi est observé le rôle de l'archevêque Berthold de Henneberg face à la réforme de l'Empire au XVe s. (Christine ROLL), tout comme, au siècle suivant des 
Réformes, celui de l'archevêque Albert de Brandebourg (Rolf DECOT) et de ses successeurs, particulièrement lors des diètes d'Empire (Maximilian LANZINNER) et, cas plus intéressant encore, lors des diètes princières (Josef LEEB) et des réunions des cercles d'Empire (Helmut NEUHAUS). L'intérêt particulier du second volume est de confronter cet assemblage de droits, privilèges, préséances, présidences et territoires rassemblés au cours du Moyen Âge à l'épreuve de la Réforme et de la confessionnalisation des XVIe et XVIIe ss. (Georg SCHMIDT, Konrad AMANN). Or, on s'aperçoit en définitive que catholiques et protestants se sont, semble-t-il, accordés à reconnaître à l'institution mayençaise un rôle stabilisateur et pondérateur, ce qui va jusqu'à se traduire dans une architecture et un urbanisme d'équilibre dans la ville même de Mayence (Walter G. RÖDEL) 